\title{
Health Related Quality of Life of Women with Cervical Cancer
}

\author{
Wanessa Cassemiro Fernandes ${ }^{1}$ \\ Miako Kimura²
}

This cross-sectional study aimed to evaluate the health related quality of life (HRQoL) of women with cervical cancer and to identify predictors of quality of life. Between November 2008 and February 2009, 149 women were interviewed. The instrument Functional Assessment of Cancer Therapy-Cervix Cancer (FACT-Cx) was used to assess HRQoL and, in general, the scores obtained indicated positive evaluation. The items that showed negative evaluation were: "I am interested in sex", "I feel sexually attractive", "I am afraid to have sex" and "My vagina feels too narrow or short". In multiple linear regression analysis, using the backward method, of the 18 independent variables, eight were predictive of HRQoL. Self-perceived health status was the most influential factor. Special attention should be given to the sexual dysfunctions of these women after radiotherapy.

Descriptors: Quality of Life; Uterine Cervical Neoplasms; Oncologic Nursing.

\footnotetext{
${ }^{1}$ RN, Master's Student, Adult Health Graduate Nursing Program (PROESA), Escola de Enfermagem, Universidade de São Paulo, SP, Brazil. E-mail: wacassemiro@usp.br.

${ }^{2}$ Free Lecture, Associate Professor, Escola de Enfermagem, Universidade de São Paulo, SP, Brazil. E-mail: mikimura@usp.br.
}

Corresponding Author:

Wanessa Cassemiro Fernandes

Hospital Sírio-Libanês Sociedade Beneficiente de Senhoras

Rua Luis de Toledo Piza, 656

Jardim Nossa Senhora do Carmo

CEP: 08275-070 São Paulo, SP, Brasil

E-mail: wacassemiro@usp.br 


\section{Qualidade de vida relacionada à saúde de mulheres com câncer de colo uterino}

Este estudo, de corte transversal, teve como objetivos avaliar a qualidade de vida relacionada à saúde (QVRS) de mulheres com câncer de colo uterino e identificar os fatores preditores de qualidade de vida. Foram entrevistadas 149 mulheres, no período de novembro de 2008 a fevereiro de 2009. O instrumento Functional Assessment of Cancer Therapy-Cervix Cancer (FACT-Cx) foi utilizado para avaliar a QVRS e, de forma geral, os escores obtidos indicaram avaliação positiva. Apresentaram avaliação negativa os itens: "tenho interesse em sexo", "sinto-me sexualmente atraente", "tenho medo de ter relações sexuais" e "sinto a vagina estreita ou curta demais". Na análise de regressão linear múltipla, pelo método backward, das 18 variáveis independentes, oito foram preditoras de QVRS. A autopercepção do estado de saúde foi o fator de maior influência. Atenção especial deve ser dada às disfunções sexuais dessas mulheres após a radioterapia.

Descritores: Qualidade de Vida; Neoplasias do Colo do Útero; Enfermagem Oncológica.

\section{Calidad de vida relacionada a la salud de mujeres con cáncer de cuello uterino}

Este estudio, de corte transversal, tuvo como objetivos evaluar la calidad de vida relacionada a la salud (CVRS) de mujeres con cáncer de cuello uterino e identificar los factores de predicción de calidad de vida. Fueron entrevistadas 149 mujeres, en el período de noviembre de 2008 a febrero de 2009. El instrumento Functional Asesment of Cancer Therapy-Cervix Cancer (FACT-Cx) fue utilizado para evaluar la CVRS y, de forma general, los puntajes obtenidos indicaron evaluación positiva. Presentaron evaluación negativa los ítems: "tengo interés en sexo", "me siento sexualmente atrayente", "tengo miedo de tener relaciones sexuales" y "siento la vagina estrecha o demasiada corta". En el análisis de regresión linear múltiple, por el método backward, de las 18 variables independientes, ocho fueron factores de predicción de CVRS. La autopercepción del estado de salud fue el factor de mayor influencia. Atención especial debe ser dada a las disfunciones sexuales de esas mujeres después de la radioterapia.

Descriptores: Calidad de Vida; Neoplasias del Cuello Uterino; Radioterapia; Enfermería Oncológica.

\section{Introduction}

According to the National Cancer Institute (INCA), the estimates for 2008, also valid for 2009, indicate that 466,730 new cases of cancer will occur in Brazil. Of this total, the number of new cases of cervical cancer per year is expected to be $18,680^{(1)}$, estimated to be the third most common type of cancer among women, being surpassed by skin cancers (non-melanoma) and breast cancer. In the entire world, it is the second leading type of cancer in women, with almost 500,000 new cases per year, and is responsible for the deaths of approximately 230,000 women per year(1).
The main treatments proposed for this type of cancer are radiotherapy, surgery, chemotherapy or a combination of these options ${ }^{(2)}$. Despite great developments in diagnostic and therapeutic methods, disease and the effects of its treatment still bring important consequences for the lives of these women, possibly compromising, in many ways, their well-being and quality of life.

Various factors contribute to changes in the quality of life of women with gynecological cancer: functional damage secondary to treatments such as pelvic surgery 
involving the removal of parts of the female genital anatomy and radiation, which damages the vaginal mucosa and epithelium; side effects of chemotherapy, which in part are common to radiotherapy, such as nausea, vomiting, diarrhea, constipation, mucositis, weight changes and hormonal changes, psychological factors, including erroneous beliefs about the origin of cancer, changes in self-image, low self-esteem, marital tensions, fears and worries(3).

Despite these severe problems due to cancer in the genital region, the physical and psychosocial consequences of illness and specific interventions such as radiation, have rarely been investigated in Brazil(4).

Therefore, the assessment of the health related quality of life of women with this cancer is considered of paramount importance, since it allows the identification of aspects of physical, mental and social well-being that are affected by health problems and permits the monitoring of the results of interventions, complementing the traditional methods based on morbidity and mortality(5).

Given this context, and in order to obtain knowledge to guide the planning of actions that meet the real needs of these women, the goals of this study were: to evaluate the health related quality of life (HRQoL) of women with cervical cancer and to identify sociodemographic and clinical factors and those related to sexual life, as predictors of HRQOL.

\section{Method}

This was a cross-sectional, correlational study, using a quantitative approach, performed in the Outpatient Clinic of Oncology, Radiotherapy section, of the Brazilian Institute for Cancer Control (IBCC).

The study population consisted of all patients diagnosed with cervical cancer that underwent radiotherapy (high dose rate teletherapy or brachytherapy) exclusively, adjuvant or concomitantly with chemotherapy at the previously mentioned service, between January 2006 and August 2008. Among the 246 patients treated in the period, 20 deaths were identified and therefore the population available for study consisted of 226 women.

After attempts to contact, the lack or inaccuracy of data in hospital records made it impossible to select a random sample. From the 226 patients, a non-probability sample was selected, which included those who attended the service and met the following eligibility criteria: age equal to or greater than 18 years, followed for at least three months at the time of data collection, not presenting a diagnosis of psychiatric disorders, mental or neurological illness, not being treated for neoplasia of another anatomical site or a local recurrence, not in a palliative treatment for advanced disease with poor prognosis, and agreeing to participate in research by signing the free prior informed consent form. The study sample consisted of 149 patients who met the eligibility criteria.

Data were collected between November 2008 and February 2009, through interviews, at a single time, after project approval by the Research Ethics Committee of the IBCC (Registration n.155/2008/14). All participants signed a free prior informed consent form. Initially, an instrument for sociodemographic and clinical characteristics and sexual life was applied. For the evaluation of HRQOL the questionnaire Functional Assessment of Cancer Therapy-Cervix Cancer (FACT$C x)^{(6)}$, version 4.0 was used, available in Portuguese, after authorization from the institution holding the copyright of the original and the translated version.

Although this instrument has not been validated in Brazil, it was chosen for use here as no other scale specific for cervical cancer, culturally adapted and validated, was found. The choice of FACT-Cx was also based on its multidimensional conception of HRQOL, its ease and speed of implementation and its brevity.

The FACT-Cx evaluates the functionality and satisfaction of the patient with the aspects evaluated, in relation to the preceding week. It consists of 42 items, 27 in the general module (FACT-G), grouped into the domains: physical well-being, social/family well-being and functional well-being, each with seven items, and emotional well-being with six items. The other 15 items correspond to the domain 'additional concerns', which assesses symptoms specific to the gynecological area, urinary and bowel problems, vaginal changes, concern about the treatment, diet, sexuality and self-image(6).

The response scales are Likert type, with scores ranging from 0 (not at all) to 4 (extremely). There are items constructed as negative phrases and in these cases, the score should be reversed. Domain scores are obtained by summing the scores of their items, ranging from 0 to 28 in the physical, social/family and functional well-being domains, from 0 to 24 in the emotional wellbeing domain and from 0 to 60 in the additional concerns domain. The total score of the instrument is the sum of the scores of the domains and ranges from 0 to 168 . Higher values represent better HRQoL ${ }^{(6)}$.

Data were stored and analyzed using SPSS (Statistical Package for the Social Sciences) version 17.0. The analyzes are shown below. 
- Descriptive statistics: for analysis of sociodemographic, clinical and sexual life variables and descriptions of the scores of FACT-CX. To detect the items with greater commitment, each item was analyzed individually, with those items that concentrated, at least, $20 \%$ of the women in response levels representative of a negative evaluation being considered relevant.

- Cronbach's alpha coefficient: to test the internal consistency of items and domains of FACT-Cx. The reference value adopted as acceptable was $\geq 0.60^{(7)}$.

- Multiple linear regression analysis (backward method) to identify predictors of HRQoL. Eighteen independent variables were selected, including those contained in the instrument of sociodemographic and clinical characteristics and sexual activity of patients: marital status, education level, employment status, practice of religious activities, family support network, support network in the community, leisure, tumor stage, treatment, time after radiotherapy, number of comorbidities, smoking, alcohol use, self perception of health, sexual activity, degree of importance attributed to sexual activity, age and number of children. It should be clarified that these variables are not included in the instrument FACT-Cx. Qualitative variables were treated in a dichotomous manner.

The dependent variables were the scores of FACT$C x$ (total and of the five domains). Initially, variables with $p \geq 0.10$ were removed from the model and then, those with $p \geq 0.05$. Therefore, the final predictive models were composed by the variables with a significance level of $p<0.05$. The Durbin-Watson test was used to detect the presence of serial correlation between the variables of each model.

\section{Results}

The average age of the 149 patients was 53.13 (sd $=11.53$ ) years, ranging from 19 to 88 years; $57.7 \%$ lived with their spouse or partner, $60.4 \%$ studied up to primary level of schooling and $59.5 \%$ were Catholic. The average number of children was 3.83 ( $s d=2.70$ ). As for employment status, $38.3 \%$ said they had no gainful employment, while $33.6 \%$ were employed. Regarding leisure habits, $47.6 \%$ reported taking part in recreational type activities. In relation to the disease stage, 57.7\% had locally advanced disease. Surgery and radiotherapy, with or without chemotherapy, was the treatment performed on $48.3 \%$ of women, radiotherapy alone, on $28.2 \%$ with chemotherapy and radiotherapy, on $23.5 \%$. $54.4 \%$ of them had finished radiotherapy for between one and two years. The presence of comorbidity was reported by $28.9 \%$, while the majority $(48.3 \%$ ) did not refer to any comorbidity. Arterial hypertension (43.6\%) and diabetes mellitus (21.3\%) were the most prevalent associated diseases; $56.4 \%$ were non-smokers and $27.5 \%$ former smokers, $61.7 \%$ were non-drinkers and $22.8 \%$ consumed alcohol. The majority of women (58.4\%) evaluated their health over the past four weeks as very good and $30.2 \%$ as good; $59.1 \%$ reported having no sexual activity in the last four weeks and $38.9 \%$ said they did not assign any importance to this activity.

Table 1 presents Cronbach's alpha coefficient values and the scores obtained with the application of FACT-CX.

Table 1 - Descriptive statistics of FACT-Cx total score and scores by domains and Cronbach's alpha coefficients. Sao Paulo, 2009. $(n=149)$

\begin{tabular}{|c|c|c|c|c|c|}
\hline Domains & Mean (sd) & Median & $\begin{array}{l}\text { Minimum/ } \\
\text { maximum }\end{array}$ & Possible variation & Cronbach's alpha \\
\hline Physical well-being & $25.62(3.58)$ & 27 & $3 / 28$ & $0-28$ & 0.84 \\
\hline Social/familial well-being & $25.17(4.41)$ & 28 & $1 / 28$ & $0-28$ & 0.84 \\
\hline Emotional well-being & $21.42(3.86)$ & 23 & $5 / 24$ & $0-24$ & 0.78 \\
\hline Functional well-being & $25.77(3.74)$ & 28 & $9 / 28$ & $0-28$ & 0.78 \\
\hline Additional concerns & $50.05(6.73)$ & 52 & $24 / 60$ & $0-60$ & 0.65 \\
\hline FACT-Cx total & $148.03(17.31)$ & 154 & $68 / 168$ & $0-168$ & 0.90 \\
\hline
\end{tabular}

The scores obtained in the domains and in the total FACT-CX show that, in general, the evaluations were satisfactory, considering that the mean values and medians were close to the maximum scores within the possible variations of the instrument. It was observed that, proportionally, the lowest means were obtained in the domains of 'additional concerns' (50.05/60), 'emotional well-being' (21.42/24) and 'social/familial well-being' (25.17/28).

Cronbach's alpha coefficient values ranged from 0.78 to 0.90 , the lowest value being obtained in the domain 'additional concerns' (0.65).

In the analysis of individual items, overall the ratings were positive. The items that showed greater 
compromise were: "I am interested in sex", with 51.7\% of women with answers "not at all/a little bit"; "I feel sexually attractive", answered by $29.5 \%$ as "not at all/a little bit", "I am afraid to have sex" with $28.8 \%$ of responses at "quite a bit/very much" and "My vagina feels too narrow or short", with $20.9 \%$ of responses at "quite a bit/very much".

Table 2, below, presents the final models of multiple regression analysis for the total score and domain scores of the FACT-Cx, processed with the criterion of $p \geq 0.05$ for exclusion of variables.

Table 2 - Multiple linear regression analysis of factors associated with the total score and with each domain score of the FACT-Cx. Sao Paulo, 2009.

\begin{tabular}{|c|c|c|c|c|}
\hline Variables that remained in the models & $\beta$ coefficient & $p$ value & $\mathbf{R}^{2}$ & Durbin-Watson \\
\hline \multicolumn{5}{|l|}{ FACT-Cx total } \\
\hline Leisure & 4.275 & 0.005 & 0.25 & 2.127 \\
\hline Self-perceived health status & 23.969 & 0.000 & & \\
\hline \multicolumn{5}{|l|}{ Physical well-being domain } \\
\hline Self-perceived health status & 5.434 & 0.000 & 0.28 & 2.152 \\
\hline Sexual activity & 1.272 & 0.014 & & \\
\hline \multicolumn{5}{|l|}{ Social/familial well-being domain } \\
\hline Self-perceived health status & 4.689 & 0.000 & 0.14 & 2.020 \\
\hline Importance attributed to sexual activity & -1.836 & 0.009 & & \\
\hline \multicolumn{5}{|l|}{ Emotional well-being domain } \\
\hline Leisure & 0.983 & 0.007 & 0.11 & 2.146 \\
\hline Time after radiotherapy & -1.522 & 0.031 & & \\
\hline Smoking & 2.587 & 0.002 & & \\
\hline \multicolumn{5}{|l|}{ Functional well-being domain } \\
\hline Self-perceived health status & 4.505 & 0.000 & 0.10 & 1.987 \\
\hline \multicolumn{5}{|l|}{ Additional concerns domain } \\
\hline Marital status & 3.310 & 0.011 & 0.23 & 1.824 \\
\hline Leisure & 1.660 & 0.006 & & \\
\hline Presence of comorbidity & -2.374 & 0.032 & & \\
\hline Smoking & 2.960 & 0.029 & & \\
\hline Self-perceived health status & 5.583 & 0.001 & & \\
\hline Sexual activity & 2.843 & 0.035 & & \\
\hline
\end{tabular}

Among the 18 variables that comprised the initial regression model, eight were independent predictors of HRQoL: self-perceived health status, leisure, smoking, sexual activity, importance attributed to sexual activity, time after radiotherapy, marital status and presence of comorbidities. Self-perceived health status was the main predictor variable of the HRQoL of women in this study, and the one that remained in the final models of FACT-Cx total and in four domains: physical wellbeing, social/familial well-being and additional concerns. Observing the $\beta$ coefficients, it was also noted that it was the main contributing factor to the variation of scores, allowing the estimation, that to have a good/very good perception of health status increases the total score of HRQoL by almost 24 points and the scores of the four areas mentioned above by approximately 5 points. The Durbin-Watson coefficients close to 2 indicate that none of the final models had serial correlation between the remaining variables.

\section{Discussion}

The reliability of the FACT-Cx instrument, used to assess HRQoL of women in this study, was previously reviewed for internal consistency of the items and domains, by means of Cronbach's alpha coefficient. The FACT-Cx achieved alpha coefficients $\geq 0.78$ in three of the four areas and 0.90 in the total of the items, which represents high reliability. In the specific domain "additional concerns", the alpha obtained was 0.65, a satisfactory value, if considered that a coefficient of at least 0.60 may reflect acceptable reliability ${ }^{(7)}$.

It should be emphasized that no studies were found that had examined the reliability of the FACT instrument with its specific module for cervical cancer, which makes comparisons impossible. For the general module (FACT-G), the following values of alpha are reported: 0.82 (physical well-being), 0.69 (social/familial wellbeing), 0.74 (emotional well-being), 0.80 (functional 
well-being) and 0.89 (FACT-G total) ${ }^{(8)}$. Another study using version 4 in Spanish identified the following alpha values: 0.91 (physical well-being), 0.81 (social/ familial well-being), 0.78 (emotional well-being), 0.82 (functional well-being) and 0.89 (FACT-G total)(9). In a Brazilian study with patients diagnosed with head and neck cancer, alpha values between 0.71 and 0.75 were observed for the domains and 0.86 for the total(10). With minor variations, the values obtained in this study were similar to those previously reported, being higher than the corresponding ones in the social/familial domain (0.85).

Considering the mean values in relation to the maximum possible values, the instrument FACT-CX showed that, in general, patients evaluated their HRQoL positively. However, the data revealed that the items of the additional concerns domain: interest in sex, fear of having sex, feeling less sexually attractive, and feeling the vagina too narrow or short were those that concentrated the highest percentage of negative evaluations.

The presence of sexual dysfunction is common in women affected by cancer, even after the termination of treatment. Approximately 40 to $100 \%$ of individuals with cancer have sexual dysfunction after diagnosis and treatment ${ }^{(3)}$. This is because the cancer and the various oncological treatments affect the same areas that determine the sexual response: the body, the mind and the relationship between them ${ }^{(11)}$, causing a strong impact on the sexuality of these people.

To attribute importance to sexual activity was a predictor of lower social/familial well-being. It was estimated that to give importance to the sexual life decreases the score of that domain by nearly two points. The social/familial well-being domain comprises the relationship with friends and family, and includes the relationship with the partner and the satisfaction with the sexual life. The majority of women in this study lived with their spouse or partner, however, did not maintain sexual activity, probably due to the sexual problems already mentioned. The majority of them also reported that they gave little or no importance to sexual activity. Thus, not to give importance to sexual activity that they did not have, or did not want, might be a way of preserving a sense of well-being in the relationship with the partner.

Table 2 shows that self-perception of health status was the variable that was present in four of the five final predictive models, being the most important factor for the increase in HRQoL among women in this study. Similar results were observed in a recent study that also found the perception of health status among the predictors of overall HRQoL in Latin American women survivors of cervical cancer(12).

Despite its subjective nature, the self-assessment of health status is considered a valid and reliable measurement, sensitive to change, that reflects the objective health status(13). This form of evaluation has been used in health research because it has been shown to be an excellent predictor of functional impairment and even death in the elderly ${ }^{(13)}$ and in patients with advanced stage cancer ${ }^{(14)}$.

Leisure was a factor associated with overall HRQoL, as well as with the emotional well-being and additional concerns domains. All study participants mentioned some kind of leisure, and the recreational activities, such as watching television, were mentioned by most of them (71-47.6\%). Probably, individual factors such as age, socioeconomic status and educational level had an influence on the patterns found for the use of free time. Lack of leisure may facilitate or accentuate loneliness, somatic complaints and difficulty in maintaining interpersonal relationships(15). It can therefore be understood that fun and entertainment, the possibility of alleviating tension and forgetting problems provided by leisure have beneficial effects on HRQoL.

The time since finishing radiotherapy was a factor inversely associated with emotional well-being, signifying that, in this sample, to have less than a year since treatment completion increases the emotional well-being. At the time of interview, 81 (54.4\%) patients were between the first and second year post-treatment. This period is of great importance for coping with difficulties arising from surgery or radiotherapy, because it is expected that, during this time, the women recover from the acute effects of treatment and return to their daily routine. These factors, coupled with the fact that, when undergoing radiotherapy, patients have the hope of improvement and of a gradual return to normality, could explain the association found between shorter time after treatment and greater emotional well-being.

Most women in this study denied smoking (84$56.4 \%$ ), and the fact of not being a smoker showed an association with a better HRQoL evaluation in the emotional well-being and additional concerns domains.

Epidemiological studies report that smoking is one of the most important risk factor for the development of cervical cancer. Although the organs most directly exposed to tobacco smoke are the most affected, other tissues, such as bladder, cervix and pancreas, are also at risk ${ }^{(16)}$. It is inferred, therefore, that smoking affects 
women's health in a broad way and that its effects not only compromise the duration of life, but also its quality.

In this study, 83 women (55.7\%) lived with their spouse or partner. Marital status was a predictive factor in the additional concerns domain, indicating that the presence of a partner creates greater comfort and emotional support for patients diagnosed with cervical cancer.

For these women, the presence of the sexual partner is highly important when it comes to creating a healthy environment where they can feel integrated into the family context ${ }^{(17)}$. It is believed, therefore, to be of great importance that health professionals understand the role of the family, especially the spouse or partner, as providers of affection and physical, emotional and social support, essential for a good quality of life, and act together with family members in order to provide better assistance to women with cancer.

In this study, $51.7 \%$ of patients presented one or more comorbidities, the most frequent being arterial hypertension (43.6\%) and diabetes mellitus (21.3\%). Coexistence of cancer and other health problems contribute to a worse HRQoL evaluation specifically in the additional concerns domain.

This association was expected, since, intuitively, it can be inferred that the interaction between the clinical presentation and treatment of coexisting diseases have cumulative and deleterious effects on quality of life, accentuating the specific concerns related to cancer.

\section{Conclusions and final considerations}

The results presented permit the conclusion that, overall, the women with cervical cancer that participated in this study positively evaluated their HRQoL. However, significant alterations in sexual functioning were detected, more related to the psychosocial context than to the physical.

The predictive factors of HRQoL identified in the multiple linear regression analysis were: self-perceived health status, leisure, sexual activity, the importance attributed to sexual activity, time after radiotherapy, smoking, marital status and presence of comorbidities. These factors had varying intensities of effect on global HRQoL and in the different domains. Self-perceived health status was the main predictive factor influencing the overall HRQoL and all domains, except the emotional well-being domain.

However, it must be considered that the predictive models resulting from multiple regression analysis showed low explanatory power, indicating that other factors were also influencing the HRQoL of these women.

The cross-sectional, correlational design of the study failed to establish causal relationships between study variables. In view of difficulties in locating the patients enrolled in the service, the sample could not be randomly selected. The 149 women included in the study represented $66 \%$ of patients being monitored between January 2006 and August 2008, however, they can not be considered representative of the population served, due to the selection bias present in non-random samples.

Despite these limitations, the results of the study are considered important, since they bring information still little known in the country, on the HRQoL of women with cervical cancer and the factors that, positively or negatively, affect different areas of their lives.

It is noteworthy that the predictive factors of HRQoL identified in this study should be the focus of more attention in the health care practice and may represent starting points for future studies that address, in depth, the different aspects of quality of life of cancer patients.

\section{Acknowledgments}

To Dr. Sylvia Radwanski Stuart, head of the Department of Radiotherapy of the Brazilian Institute for Cancer Control, for supporting the realization of this work at the institution.

\section{References}

1. Instituto Nacional de Câncer (INCA). Estimativa 2008: Incidência de câncer no Brasil -2009. [acesso em: 23 fev 2009]. Disponível em: http://www.inca.gov.br/estimativa/2008/ versaofinal.pdf

2. Ministério da Saúde (BR). Secretaria Nacional de Assistência à Saúde. Instituto Nacional de Câncer. Coordenação de Prevenção e Vigilância (Conprev). Falando sobre câncer do colo do útero. Rio de Janeiro: MS/INCA; 2002. 59 p. [acesso em: 15 out 2009]. Disponível em: http://bvsms.saude.gov.br/bvs/publicacoes/ inca/falando_cancer_colo_utero.pdf

3. National Cancer Institute. Sexuality and Reproductive Issues - Factors affecting sexual function in people with cancer. [database on the Internet]. United States: U.S. National Institutes of Health. [cited 2009 Fev 06]. Available from: http:// www.cancer.gov/cancertopics/pdq/supportivecare/sexuality/ HealthProfessional/page3

4. Barros GC, Labate RC. Repercusiones psicológicas relacionadas al tratamiento de braquiterapia en mujeres con 
cáncer ginecológico: un análisis de la producción de 1987 a 2007. Rev. Latino-Am. Enfermagem [serial online] 2008 NovDec [aceso en: 11 Out. 2009]; 16(6): [6 screens]. Disponible en: http://www.scielo.br/pdf/rlae/v16n6/pt_18.pdf

5. Minayo MCS, Hartz ZMA, Buss PM. Qualidade de vida e saúde: um debate necessário. Ciênc. saúde coletiva 2000; 5(1): 7-18.

6. Webster K, Cella D, Yost K. The Functional Assessment of Chronic Illness Therapy (FACIT) Measurement System: Properties, applications, and interpretation. Health Qual Life Outcomes [serial on the Internet]. 2003 [cited 2009 Fev 23]; 79(1): [about 7 screens]. Available from: http://www.hqlo.com/ content/pdf/1477-7525-1-79.pdf

7. Hair JF, Anderson RE, Tatham RL, Black WC. Análise multivariada de dados. Porto Alegre (RS): Bookman; 2005. p.89-127.

8. Cella D, Tulsky DS, Gray G, Sarafian B, Linn E, Bonomi A, et al. The Functional Assessment of Cancer Therapy Scale: development and validation of the general measure. J Clin Oncol. 1993; 11:570-9.

9. Dapueto JJ, Francolino C, Servente L, Chang Ch, Gotta I, Levin R, et al. Evaluation of the Functional Assessment of Cancer Therapy-General (FACT-G) Spanish Version 4 in South America: Classic Psychometric and Item Response Theory Analyses. Health Qual Life Outcomes 2003; 1:32.
10. Sawada NO. Qualidade de vida dos pacientes com câncer de cabeça e pescoço. [Tese]. Ribeirão Preto (SP): Escola de Enfermagem de Ribeirão Preto/USP; 2002.

11. Cancernetwork [homepage on the Internet]. New York: American Business Media, Inc.; c1996-2009 [updated 2008 Jun; cited 2008 Jun 22]. Available from: http://www.cancernetwork. com/display/article/10165/101698

12. Ashing-Giwa KT, Tejero JS, Kim J, Padilla GV, Kagawa-Singer $M$, Tucker MB, et al. Cervical cancer survivorship in a population based sample. Gynecol Oncol 2009; 112(2): 358-64.

13. Idler EL, Benyamini Y. Self-rated health and mortality: a review of twenty-seven community studies. J Health Soc Behav. 1997; 38:21-37.

14. Shadboldt B, Barresi J, Craft P. Self-rated health as a predictor of survival among patients with advanced cancer. J Clin Oncol. 2002; 20(10):2514-9.

15. Jannuzzi FF, Cintra FA. Atividades de lazer em idosos durante a hospitalização. Rev Esc Enferm USP. 2006; 40(2):179-87.

16. Albring L, Brentano JE, Vargas VRA. O câncer do colo do útero, o Papilomavírus Humano (HPV), seus fatores de risco e as mulheres indígenas Guarani: estudo de revisão. Rev Bras Anal Clin 2006; 38(2):87-90.

17. Almeida LHRB, Pereira YBAS, Oliveira TA. Radioterapia: percepção de mulheres com câncer cérvico-uterino. Rev Bras Enferm 2008; 61(4):482-7. 